\title{
AN OPTIMISED COMPETENCY FRAMEWORK TO PREPARE STUDENTS FOR EMPLOYMENT
}

\author{
Dominic Palmer-Brown ${ }^{1}$, Fang Fang Cai ${ }^{2}$, Preeti Patel ${ }^{1}$ \\ ${ }^{1}$ London Metropolitan University (UNITED KINGDOM) \\ ${ }^{2}$ Anglia Ruskin (UNITED KINGDOM)
}

\begin{abstract}
The language of competency is heavily utilised by employers when considering staff selection, appraisal, continued professional development, technical training and personal development. However, students and new graduates are not proficient in this language and therefore face challenges when entering the employment market. Competency frameworks exist in virtually all professional and employment sectors, but are particularly prolific in science, medicine, engineering, computing and IT, where they are often aligned to continuing professional development and certification.

In this paper, we present a competency framework developed by adapting a number of existing professional competency frameworks used within the IT industry. Our competency framework is designed to be used by and for students on a degree programme with an embedded work-related learning course. The framework has two specific aims: firstly, that it must be usable by students for self-evaluation and self-regulation purposes, and secondly, that it must allow for the support and dispensing of developmental feedback.

We also present the results of a study conducted to test the competency framework with 125 students on a Computing-related degree. Understanding, through cluster and correlation analysis, the way in which students perceive their own competencies has led us to optimise our framework to include the twelve most significant competencies within the Academic, Workplace and Personal Effectiveness categories. In our study, it is the Personal Effectiveness competencies such as 'self-management' 'adaptability' and 'integrity' that feature prominently and it is this category of competencies that students find the most challenging to refine.
\end{abstract}

Keywords: competency, self-evaluation, framework, work-related learning.

\section{INTRODUCTION}

The concept of 'competency' has materialised outside the higher education system to characterise an individual's set of skills and proficiencies that are relevant to employability. The term competency is defined according to its primary purpose and we cite the following as it encompasses the developmental aspect that relate to our study:

A cluster of related knowledge, skills, and abilities that affects a major part of one's job (a role or responsibility), that correlates with performance on the job, that can be measured against well-accepted standards, and that can be improved through training, development, and experience. ${ }^{1}$

Several models have been introduced to enhance the so-called process skills and competences by stimulating students to apply their knowledge. For example, project-led education (PLE) uses teambased activity to solve complex large-scale open-ended problems whereas problem-based learning (PBL) uses structured teams solving smaller-scale tasks.

In addition, CDIO (conceive, design, implement and operate) is an engineering education model which aims to close the gap between engineering science and engineering practice; and also, strives to engender a sense of engineering professionalism. These initiatives provide a mechanism for defining academic curriculum and practices but they do not establish assessment methods and certainly not assessment feedback practices.

In [1] the focus is on a PBL pedagogy to utilise a repository of competencies against which learners are assessed. Here use is made of the repository for the ongoing evaluation of the learner's skills during three stages, namely pre-assessment, formative assessment and post-assessment. It is not

${ }^{1}$ Training Magazine, July 1996 
clear how the competencies are assessed and what forms of assessment can be used. Also in the formative assessment stage, the feedback appears to take a performance-related guise for phases of the project that students are undertaking.

A competency framework for software engineers [2], is arrived at by defining ten roles (e.g. programmer, test engineer, analyst) for which the competencies of technical, social and personal are measured. [3] have developed a useful competency framework for an Object-oriented Application Development course which facilitates the setting of assessment and the provision of feedback (in the form of grades) by the course team. However, there is no evidence given as to how the competencies have been arrived at, and it appears as though they equate to course content; certainly, they do not appear to be derived from any particular professional competency framework. Similarly, [4] have developed a framework for assessing students' competencies of a software engineering capstone project. Here again there appears to be little alignment to a professional framework.

Competency frameworks have also been proposed for other professions such as the conservationrestoration profession [5], border officers [6], medical records officer [7] and Enterprise Resource Planning [8]. In addition, competency frameworks have been developed for the purposes of informing curriculum design for Higher Education Institutions and development processes for organisations (for example [9], [10] and [11]), but these lie outside the main focus here which is to consider the use of competency frameworks for developing self-awareness of students.

\section{COMPETENCY FRAMEWORKS}

Competency frameworks exist in virtually all professional and employment sectors, but are particularly prolific in science, medicine, engineering, computing and IT, where they are often aligned to continuing professional development and certification. Professional bodies such as Institute of Engineering and Technology (IET), BCS The Chartered Institute for IT, Health and Care Professions Council (HCPC), British Medical Association (BMA), UK government bodies such as the Department for Business, Innovation and Skills (BIS) and not-for-profit organisations such as The Tech Partnership often seek to define and innumerate the standards by which professionals should work.

As a starting reference point, in the following sub-sections, we describe three examples of professional competency frameworks readily available for the various professions of Information Technology, Cybersecurity and Information Management - namely the SFIA, NICE and IISP frameworks.

\subsection{SFIA Framework}

The Skills Framework for the Information Age (SFIA) ${ }^{2}$ is the UK Government and British Computer Society (BCS, The Chartered Institute for IT) backed competency framework which describes IT roles and associated skills. SFIAPlus contains the SFIA framework of IT skills plus detailed training and development resources, providing organisations and practitioners the framework required for defining job profiles. Although introduced in 2003 following collaborative development, the SFIA framework is now in its $6^{\text {th }}$ version (launched in July 2015) and has been revised to include cyber security skills more prominently.

The SFIA framework consists of six categories: Strategy and Architecture, Change and Transformation, Development and Implementation, Delivery and Operation, Skills and Quality, Relationships and Engagement. Each of these categories is further divided into sub-categories, mapping out 97 separately identifiable skills.

Each skill is described at one or more of seven levels of responsibility, namely: Follow; Assist; Apply; Enable; Ensure and advise; Initiate and influence; and Set strategy, inspire and mobilise. Each of these responsibility levels also has a generic description detailing the level of autonomy, influence, complexity and business skills required. Skills apply at one or more of the seven levels - the higher the level, the more senior the practitioner.

The SFIA framework is seen to be a common language for individuals and organisations to define skills, abilities and expertise in a consistent way. It can help organisations in creating roadmaps, Human Resources planning, career development planning and configuring mixed teams. It can also help in workforce recruitment by being able to help create job profiles and descriptions.

\footnotetext{
${ }^{2}$ The SFIA website: www.sfia-online.org
} 


\subsection{NICE Framework}

The National Cybersecurity Workforce Framework ${ }^{3}$ is promoted and updated by the National Initiative for Cybersecurity Education (NICE) which falls under the umbrella of the US Department of Homeland Security. The NICE framework has similar goals to the SFIA framework - they both provide a common language with which employers, employees, recruiters, students and training providers are able to identify and standardise the required tasks and skills. However, whilst SFIA is for the IT professional, NICE is developed for the cybersecurity workforce.

The NICE framework organises cybersecurity work into 32 Speciality Areas and these are grouped into 7 categories based on similarity. For each Speciality Area, the framework presents a standard set of required tasks and knowledge, skills and abilities (KSAs). The 7 categories are Collect and Operate, Analyse, Protect and Defend, Operate and Maintain, Securely Provision, Investigate and finally Oversight and Development. An example of the 32 Speciality Areas is Digital Forensics which falls within the Investigate category. The framework then goes on to provide 55 KSAs for Digital Forensics, such as, knowledge of data carving tools and techniques (e.g. Foremost).

The NICE framework uses the term competency to mean the areas of expertise required for successful performance of a job function. This is not as fine-grained as usually expected, for example, in the case of the digital forensics Speciality Area, competencies listed include, amongst 18 others, Criminal Law and Cryptography.

\subsection{IISP Framework}

The Institute of Information Security Professionals (IISP) ${ }^{4}$ have developed a "skills framework to describe the range of competencies expected of Information Security and Information Assurance Professionals in the effective performance of their roles". It defines the skills and capability expected of security professionals in practical application and not simply an assessment of their knowledge.

The IISP framework defines 9 subject disciplines - each of which are further defined by a number of skills groups. For example, the subject discipline Information Security Management is defined by the groups: Governance, Policy and Standards and Information Security Strategy amongst others.

The IISP framework differs from the SFIA and NICE in that it includes a scoring mechanism based on a 4 level measurement, where Level 1 is Awareness, Level 2 is Basic Application, Level 3 is Skillful Application and Level 4 is Expert.

The three professional competency frameworks all share the particular common theme of systematically itemising, at varying degrees of detail, the entire breadth of skills and knowledge that a practicing professional is required to exhibit. However, this results in frameworks that are huge and unwieldy for the purposes of developing students within an academic programme. Although SFIA does include a levelling of expertise (from level 1 to 7 ) where an entry-level professional could be a new graduate and therefore deemed to be at level 1 , the detail with which the skills are represented would make them unusable by a novice. In addition, it is clear that the frameworks adhere to their own specific terminology; for example, NICE KSAs can be interpreted as competencies in SFIA. This again means that the use of the framework for personal development can be a daunting prospect to a novice. Professional frameworks have goals that are beyond just personal development - they enable an organisation to standardise skills for performance measurement, for reward schemes, for recruitment, for targeted training and for organisational efficiency and productivity. In addition, professional frameworks are very commonly aligned to industry certification and therefore fulfil an entirely different need.

For these reasons, there is a requirement to adapt and arrive at a competency framework which can be readily utilised within an academic programme in the context of a work-related learning platform.

\subsection{A competency framework for work-related learning students (CFWRL)}

This section presents a competency framework designed to be used by and for students on a workrelated learning module. The framework has two specific aims:

- It must be usable by students for self-evaluation and self-regulation purposes.

\footnotetext{
${ }^{3}$ The Framework can be utilised via an interactive website: https://niccs.us-cert.gov/training/tc/framework/

${ }^{4}$ The IISP website: www.iisp.org
} 
- It must allow for the support and dispensing of developmental feedback.

The framework has drawn from the NICE framework in terms of the separation of competencies into the associated sections: Personal Effectiveness competencies, Academic competencies and Workplace competencies. However, whereas NICE views these as tiers (that are presumably developed by individuals over time), in CFWRL we take the view that students on a work-related learning module develop their academic and workplace competencies in parallel and that furthermore, personal effectiveness competencies are developed in all areas of a student's environment. Within the NICE framework, an additional two tiers, namely 4 and 5 are related to industry-wide technical competencies and industry-sector functional areas respectively. Within CFWRL a general section labelled Job Role competencies is included as each work-related learning opportunity will differ from the next. Fig. 1 depicts the four categories contained within CFWRL and the competencies included in each category. The competencies incorporated here are the most widely used across all the professional frameworks but have been assimilated and labelled in a customised way for optimum use by students and academic tutors. The total number of competencies has been limited to twenty as anything more may an adverse effect on student engagement.

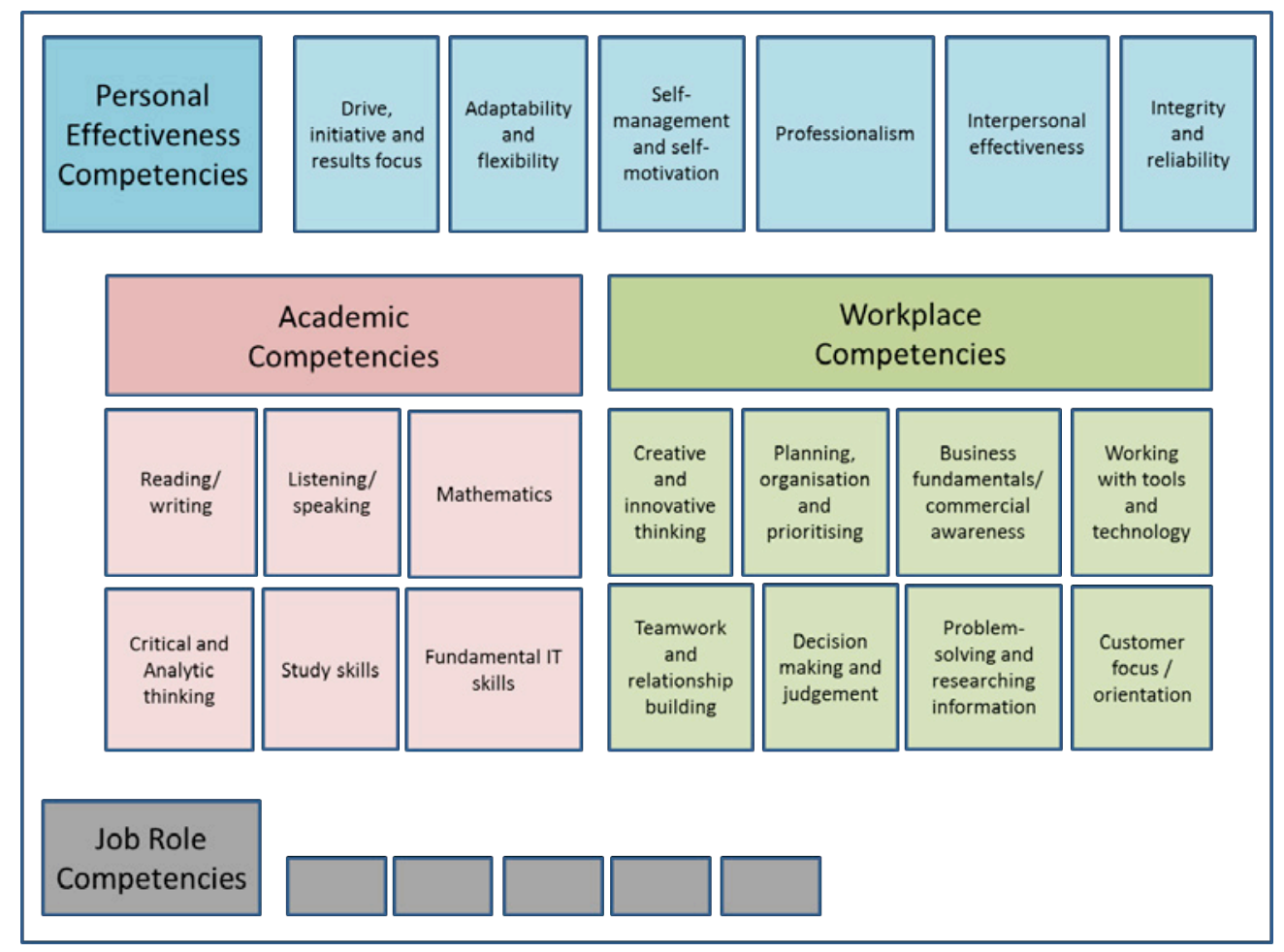

Figure 1 Competency Framework for Work-Related Learning (CFWRL).

\section{METHOD}

A set of developmental feedback cues were designed for use alongside CFWRL and formed the basis for a study of a group of Computing students. A purposive sampling of participants was used to include students following a Computing degree in which the majority of the sample had undertaken a work-related learning (WRL) module. 102 such students were initially identified with another 30 students constituting a control group. All students were surveyed on their perception of competencies within the framework. The universally employed Likert scale was used to measure the level of skill as perceived by individual students for the 20 competencies in the framework. The decision to use a 7point scale was taken as competence is seldom a straightforward question of 'can or cannot'; rather it is useful to allow a student to evaluate each competency at a broader range of skill level. The advantage of simplicity of use was deemed to outweigh the disadvantage of individuals' avoidance of choosing at the extremes of the scale. The self-evaluative survey based on the competency framework was administered to all students at the beginning and also at the end of their WRL experience. The control group were also treated in the same way in that they were asked to complete the survey at the beginning and end of the semester. Students were required to provide a rating of their chosen skill level from 1 (no skill) to 7 (highly skilled). 
All students were asked to respond to the survey at approximately the same time prior to the start of the bulk of their WRL experience. Students were requested to include their names on the response and to answer as honestly as possible. The sample was then randomly divided into two, with one half of the group to be given developmental feedback during the course of 8-10 weeks. Wherever possible the feedback was given face-to-face, but on occasion these sessions were conducted by telephone or video-chat. Some students had more than one feedback session but no student had more than three.

\subsection{Optimising the Competency Framework}

A recurring factor during interactions with students in the sample was that they experienced difficulties when attempting to address all the 20 competencies in a relatively short span of time. Therefore, we now proceed to carry out further investigation into the competency framework and consider how competencies are connected to each other. Our aim is to segment and potentially (re)categorise the competencies so that student experience initiatives can be better targeted. Popular statistical tools for data analysis which focus on investigating the relationships between variables are cluster analysis and correlation analysis. The cluster analysis of variables uses the Euclidean distance between the scores on the variables to determine which variables are close to each other. In terms of our competency framework, clustering will allow us to determine the degree of association between the scoring of competencies across all 125 students. The correlation matrix of variables uses correlations, essentially normalised sum of cross products of scores on pairs of variables. In terms of our competency framework, correlations will give us an alternative measure to allow us to highlight those competencies which are strongly related to each other. Cluster and correlation analysis are similar but different measures of the closeness of the association between variables. We, therefore, utilise both these measures to give us two ways of understanding of the student self-rating results.

\subsubsection{Hierarchical Cluster Analysis using Dendograms}

We carried out a hierarchical cluster analysis of the 20 competency variables. In order to understand this better and to visualise the cluster analysis of the variables, a dendogram was generated which displays the distance level at which there are combinations of clusters. Fig. 2 is the SPSS derived output, with the 20 'before' competencies labelled in abbreviated form on the $y$-axis, which shows that there are indeed strong groupings of variables.

It is possible to consider these groupings at various levels, at one extreme (towards the right of the diagram) we have two cluster groups and at the other extreme (towards the left of the diagram) we could view the majority of competencies as being either clustered in pairs or singular. There are many 'levels' in between these two extremes and in Fig. 2 we present 3 possible levels: A, B, and C. Here level $A$ is a fine-grained approach in which a total of 16 competencies can be abstracted as being grouped together. At level $\mathrm{C}$, the groupings broadly correspond to our three original categories of Academic, Workplace and Personal Effectiveness, whilst Level B is an intermediate level. Strikingly, some competencies stand out as not being closely related to others, e.g. 'professionalism', 'interpersonal effectiveness', 'self-management and self-motivation'. The competency of 'critical and analytic thinking' also does not have similar student scores to most other competencies. During discussion, the students did appear to find these competencies difficult to relate to and contextualize.

In summary, the cluster analysis of prior competency scoring indicates some strong groupings of the variables within our 3 competency headings, confirming that the students often give similar scores to competency questions prior to their starting the module. However, the prior module competency scores on some variables are not closely related to those of other members of their competency group, indicating that these variables are in some way seen as different by students. Thus, while it would appear that there is some redundancy in the some of the before module questions (as responses are closely related), there are some competencies that benefit from separate questions. 


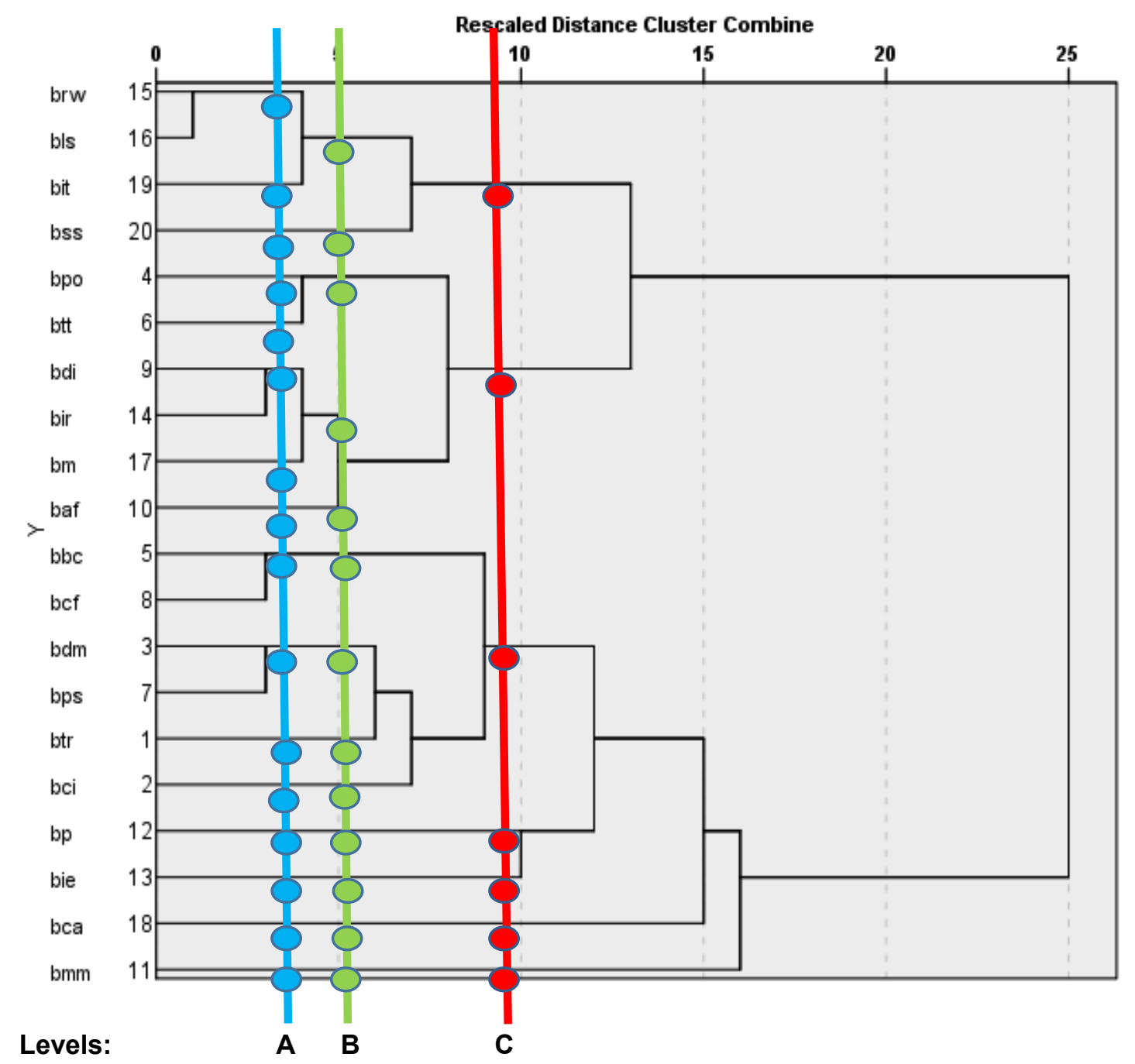

Figure 2 Annotated Dendogram of 'before' competencies.

On the basis that

1 We have established that variable responses are indeed clustered and therefore there is potential for eliminating redundancy,

2 There is scope for optimising the groupings whilst still preserving the variability of competencies,

3 Students might respond more successfully to fewer targets,

we now proceed to the use of correlation analysis as a further tool to aid in the refinement of the competency framework.

\subsubsection{Correlation Analysis using Correlation Matrix}

The competency framework has 20 competency questions, arranged under 3 main headings, (i) Workplace competencies (8 questions), (ii) Personal Effectiveness competencies (6 questions) and (iii) Academic competencies (6 questions).

Many of the 20 competencies were expected, a priori, to be highly correlated. In fact, when we produced the correlation matrix in Table 1, many of the 190 correlations were indeed large and positive. Table 1 shows that some 28 of these correlations were greater than 0.8 (i.e. within a $95 \%$ confidence interval of an exact correlation of 1.0), indicating that these pairs are measuring much the same thing in the eyes of the students. Moreover, many of the eight Workplace competencies were highly correlated, giving confidence that they were indeed measuring the same inherent competencies useful in the work environment. Thus, it might be deemed desirable to redefine these questions to 
incorporate the essence of both members of the pair, thereby reducing the number of competency questions.

\subsubsection{Reducing Highly Correlated Variables}

Dimensionality reduction is a process by which the number of variables or dimensions is systematically removed for modelling purposes. This process is useful in our case because for the student responses to the 20 competencies there are many of the 190 correlations that are strong. It is therefore possible to consider reducing the number of variables without greatly losing information. The process relies on the generation of a correlation matrix and the aim here is to find the most representative variables from pairs of highly correlated variables and discarding the 'redundant' or less correlated variables.

From the correlation matrix, we produced a list (Table 2) of the 28 highly correlated (to 0.8 ) pairs and considered the amalgamation, or replacement, or preservation of competencies both from a pairwise approach and from a more wider perspective of sets of competencies. We have confidence in this process where the correlations are above 0.8 . Inspecting Table 2 and first considering the most highly correlated pair of variables ( $r=0.982)$, namely 'reading and writing' and 'listening and speaking', we amalgamated them into a new 'interpersonal communication' skill. Next, we considered the pair with the next highest correlation ( $r=0.929)$, namely 'business fundamentals/commercial awareness' and 'customer focus/orientation', we amalgamated these into a 'commercial awareness' competency. We carried on considering variables in decreasing order of strength of correlation.

Considering Table 2, the Workplace competencies (in green) are very highly correlated amongst themselves, so that there is a strong case of merging and consolidating (and where necessary relabelling) them.

Again, from Table 2, in the Personal effectiveness category (in blue), many of the competencies do not feature in this list as they do not correlate strongly to each other, and the remainder only correlate with some of the competencies in the other two categories. Importantly, the competencies of 'professionalism', 'self-management and self-motivation' and 'interpersonal effectiveness' do not correlate to any other competency.

In the Academic category (in orange), there is very little correlation between pairs of these competencies and those in the other two categories. Also, the competencies of 'fundamental IT skills' and 'study skills' do not appear in Table 2 as they are not significantly correlated to any other competency.

Fig. 3 includes an indication of how the process of amalgamation proceeded with some re-labelling of competencies. As can be seen from the diagram, some unification took place by reducing a pair of highly correlated variables into a single one with some re-labelling based on student comments in feedback sessions and educator judgement. Three of the original competencies, namely 'professionalism', 'study skills' and 'IT skills' did not appear in the highly correlated variable list as being above the correlation threshold of 0.8 and are therefore depicted separately to the right most side of the figure and included as they are in the final set of competencies. 
Table 1 Correlation Matrix of 'before' competency scores.

\begin{tabular}{|c|c|c|c|c|c|c|c|c|c|c|c|c|c|c|c|c|c|c|c|c|}
\hline & $\mathrm{Btr}$ & $\mathrm{Bci}$ & $\mathrm{Bdm}$ & Bpo & $\mathrm{Bbc}$ & $\mathrm{Btt}$ & Bps & Bcf & Bdi & Baf & $\mathrm{Bmm}$ & $\mathrm{Bp}$ & Bie & Bir & Brw & Bls & $\mathrm{Bm}$ & Bca & Bit & Bss \\
\hline Btr & 1 & $.829^{\circ \prime}$ & $.847^{\prime \prime}$ & $.674^{\prime \prime}$ & $.727^{* *}$ & $.501^{\prime \prime}$ & $.811^{\prime \prime}$ & $.827^{\prime \prime}$ & $.768^{\prime \prime}$ & $739^{\circ}$ & $.669^{\prime \prime}$ & $.716^{\prime \prime}$ & $.759^{\prime \prime}$ & $.723^{\prime \prime}$ & $.562^{\circ}$ & $.525^{\circ}$ & $.569^{\prime \prime}$ & $642^{\circ}$ & $.444^{\prime \prime}$ & $.417^{\prime \prime}$ \\
\hline Bci & & 1 & $.742^{* *}$ & $.645^{\circ}$ & $.733^{* *}$ & $.640^{\circ}$ & $.851^{* *}$ & $.812^{* \prime}$ & $.727^{\prime \prime}$ & $.836^{\prime \prime}$ & $.637^{* \prime}$ & $.733^{\circ "}$ & $.768^{* \prime}$ & $.717^{\prime \prime}$ & $.373^{* \prime}$ & $.364^{\prime \prime}$ & $.649^{\prime \prime}$ & $.449^{\prime \prime}$ & $.297^{\prime \prime}$ & $.218^{\circ}$ \\
\hline Bdm & & & 1 & $.803^{\prime \prime}$ & $.839^{\prime \prime}$ & $.596^{\circ}$ & $.897^{\prime \prime}$ & $826^{\prime \prime}$ & $.748^{\prime \prime}$ & $.708^{\prime \prime}$ & $.824^{\prime \prime}$ & $699^{\prime \prime}$ & $.549^{\prime \prime}$ & $.629^{\prime \prime}$ & $.431^{\prime \prime}$ & $392^{\prime \prime}$ & $485^{\circ}$ & $486^{\prime \prime}$ & $203^{\circ}$ & $477^{\prime \prime}$ \\
\hline Bpo & & & & 1 & $.821^{* *}$ & $.849^{\circ}$ & $.828^{\prime \prime}$ & $.772^{* \prime}$ & $.792^{\prime \prime}$ & $.702^{\circ}$ & $.750^{\circ}$ & $.462^{\prime \prime}$ & $379^{* *}$ & $.677^{\prime \prime}$ & $.316^{* \prime \prime}$ & $.279^{\prime \prime}$ & $.603^{* \prime}$ & $.245^{\prime \prime}$ & $.260^{\circ \prime}$ & $.334^{\prime \prime}$ \\
\hline $\mathrm{Bbc}$ & & & & & 1 & $.729^{\prime \prime}$ & $.827^{\prime \prime}$ & $.929^{\prime \prime}$ & $.702^{\prime \prime}$ & $.789^{\circ}$ & $.787^{\circ}$ & $.675^{\circ}$ & $.571^{\prime \prime}$ & $.654^{\prime \prime}$ & $.185^{\circ}$ & 135 & $.580^{\circ}$ & $291^{\prime \prime}$ & 134 & $241^{\prime \prime}$ \\
\hline $\mathrm{Btt}$ & & & & & & 1 & $.747^{\prime \prime}$ & $.677^{\prime \prime}$ & $.691^{\prime \prime}$ & $.723^{\prime \prime}$ & $.552^{\prime \prime}$ & $339^{\prime \prime}$ & $.361^{\prime \prime}$ & $.663^{\prime \prime}$ & $.221^{\circ}$ & $.233^{\prime \prime}$ & $.665^{\circ}$ & .078 & $.347^{\prime \prime}$ & $181^{\circ}$ \\
\hline $\mathrm{Bps}$ & & & & & & & 1 & $.819^{\prime \prime}$ & $.794^{\prime \prime}$ & $.780^{\circ}$ & $.752^{\prime \prime}$ & $.725^{\circ}$ & $629^{* *}$ & $.677^{\circ}$ & $391^{\prime \prime}$ & $.397^{* \prime}$ & $.597^{\prime \prime}$ & $.431^{\prime \prime}$ & $.242^{\prime \prime}$ & $364^{\prime \prime}$ \\
\hline Bcf & & & & & & & & 1 & $.795^{\prime \prime}$ & $.849^{\circ \prime}$ & $.672^{\prime \prime}$ & $.729^{\prime \prime}$ & $.759^{\circ *}$ & $.763^{* *}$ & $.292^{\prime \prime}$ & $.245^{\prime \prime}$ & $679^{\prime \prime}$ & $.431^{\prime \prime}$ & $.297^{\prime \prime}$ & 160 \\
\hline Bdi & & & & & & & & & 1 & $.839^{\circ "}$ & $.602^{\prime \prime}$ & $.567^{\circ}$ & $.608^{* \prime}$ & $.855^{\circ}$ & $.589^{\circ \prime}$ & $.551^{\circ}$ & $854^{\prime \prime}$ & $.584^{* \prime}$ & $.509^{\prime \prime}$ & $.315^{\prime \prime}$ \\
\hline Baf & & & & & & & & & & 1 & $.652^{* \prime}$ & $.701^{\prime \prime}$ & $.761^{*}$ & $.858^{\prime \prime}$ & $.327^{\prime \prime}$ & $.300^{\circ}$ & $840^{\circ}$ & $.358^{\prime \prime}$ & $.390^{\circ}$ & 135 \\
\hline $\mathrm{Bmm}$ & & & & & & & & & & & 1 & $669^{\circ}$ & $.348^{\prime \prime}$ & $.513^{\prime \prime}$ & $320^{\circ}$ & $.276^{\prime \prime}$ & $399^{\prime \prime}$ & $357^{\prime \prime}$ & .035 & $.578^{\prime \prime}$ \\
\hline Bp & & & & & & & & & & & & 1 & $.755^{\circ}$ & $.593^{\prime \prime}$ & $.332^{\prime \prime}$ & $328^{\prime \prime}$ & $430^{\circ}$ & $.572^{\prime \prime}$ & $.177^{\circ}$ & $277^{*}$ \\
\hline Bie & & & & & & & & & & & & & 1 & $.730^{\circ "}$ & $.359^{\prime \prime}$ & $.354^{\prime \prime}$ & $.614^{\prime \prime}$ & $.482^{\prime \prime}$ & $.480^{\circ}$ & .003 \\
\hline Bir & & & & & & & & & & & & & & 1 & $600^{\circ}$ & $.552^{\circ}$ & $840^{\circ}$ & $.511^{\prime \prime}$ & $.648^{\circ "}$ & $237^{\prime \prime}$ \\
\hline $\mathrm{Brw}$ & & & & & & & & & & & & & & & 1 & $.98{ }^{\prime \prime}$ & $.457^{\prime \prime}$ & $868^{\circ}$ & $.784^{\prime \prime}$ & $.744^{* \prime}$ \\
\hline Bls & & & & & & & & & & & & & & & & 1 & $.418^{\prime \prime}$ & $846^{\circ}$ & $.794^{\prime \prime}$ & $.730^{\circ}$ \\
\hline $\mathrm{Bm}$ & & & & & & & & & & & & & & & & & 1 & $411^{\prime \prime}$ & $.545^{\prime \prime}$ & .091 \\
\hline Bca & & & & & & & & & & & & & & & & & & 1 & $.594^{\prime \prime}$ & $.643^{* *}$ \\
\hline Bit & & & & & & & & & & & & & & & & & & & 1 & $361^{\prime \prime}$ \\
\hline Bss & & & & & & & & & & & & & & & & & & & & \\
\hline
\end{tabular}


Table 2 Correlated pairs of 'before' competencies.

\begin{tabular}{|c|c|c|c|}
\hline Step & Factor & Paired correlations & \\
\hline 1 & .982 & Reading/writing & Listening/speaking \\
\hline 2 & .929 & $\begin{array}{l}\text { Business fundamentals commercial } \\
\text { awareness }\end{array}$ & Customer focus/orientation \\
\hline 3 & .897 & Decision making and judgement & $\begin{array}{l}\text { Problem solving and researching } \\
\text { information }\end{array}$ \\
\hline 4 & .868 & Reading/writing & Critical and analytic thinking \\
\hline 5 & .858 & Adaptability and flexibility & Integrity and reliability \\
\hline 6 & .855 & Drive initiative and results focus & Integrity and reliability \\
\hline 7 & .854 & Drive initiative and results focus & Mathematics \\
\hline 8 & .851 & Creative and innovative thinking & $\begin{array}{l}\text { Problem solving and researching } \\
\text { information }\end{array}$ \\
\hline 9 & .849 & Planning, organisation and prioritising & Working with tools/technology \\
\hline 10 & .849 & Customer focus/orientation & Adaptability and flexibility \\
\hline 11 & .847 & Teamwork and relationship building & Decision making and judgement \\
\hline 12 & .846 & Listening/speaking & Critical and analytic thinking \\
\hline 13 & .840 & Adaptability and flexibility & Mathematics \\
\hline 14 & .840 & Integrity and reliability & Mathematics \\
\hline 15 & .839 & Decision making and judgement & $\begin{array}{l}\text { Business fundamentals/ } \\
\text { commercial awareness }\end{array}$ \\
\hline 16 & .839 & Drive initiative and results focus & Adaptability and flexibility \\
\hline 17 & .836 & Creative and innovative thinking & Adaptability and flexibility \\
\hline 18 & .829 & Teamwork and relationship building & Creative and innovative thinking \\
\hline 19 & .828 & Planning, organisation and prioritising & $\begin{array}{l}\text { Problem solving and researching } \\
\text { information }\end{array}$ \\
\hline 20 & .827 & $\begin{array}{l}\text { Business fundamentals/commercial } \\
\text { awareness }\end{array}$ & $\begin{array}{l}\text { Problem solving and researching } \\
\text { information }\end{array}$ \\
\hline 21 & .827 & Teamwork and relationship building & Customer focus/orientation \\
\hline 22 & .826 & Decision making and judgement & Customer focus/orientation \\
\hline 23 & .824 & Decision making and judgement & Self-management and self-motivation \\
\hline 24 & .821 & Planning, organisation and prioritising & $\begin{array}{l}\text { Business fundamentals/ } \\
\text { commercial awareness }\end{array}$ \\
\hline 25 & .819 & $\begin{array}{l}\text { Problem solving and researching } \\
\text { information }\end{array}$ & Customer focus/orientation \\
\hline 26 & .812 & Creative and innovative thinking & Customer focus/orientation \\
\hline 27 & .811 & Teamwork and relationship building & $\begin{array}{l}\text { Problem solving and researching } \\
\text { information }\end{array}$ \\
\hline 28 & .803 & Decision making and judgement & Planning, organisation and prioritising \\
\hline
\end{tabular}




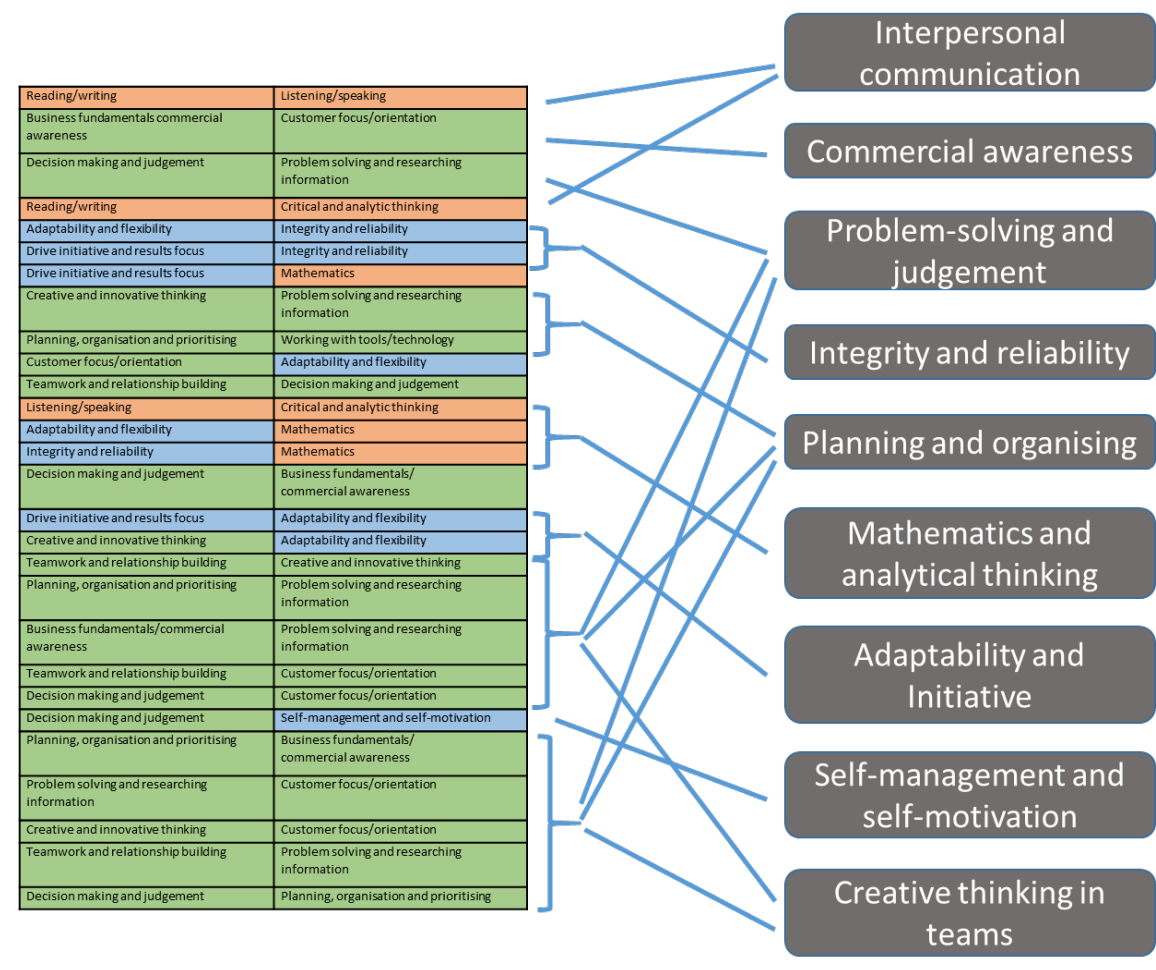

Professionalism

Study skills

IT skills

Figure 3 Optimising the 'before' competencies.

\section{RESULTS - AN OPTIMISED COMPETENCY FRAMEWORK}

The optimisation process has been performed by knowledge of domain, human/educator judgement and variable correlation analysis. It has been possible to synthesise some of the terminology of competency. Some judgement was used when amalgamating competencies, particularly for the Workplace competencies as they were extremely interlinked with each other and featured repeatedly in the correlation list. An important aim of the optimisation process was to ensure that the competency framework should be minimal, contain no overlap and yet be as comprehensive as possible. There is a small degree of arbitrariness in the distillation process in that in one or two instances there was a choice of what to include and how to label it. Educator judgement and experience as well as student commentary during developmental feedback sessions helped in these circumstances.

The optimisation process results in 12 variables; these are shown in the optimised competency framework (Fig. 4), in which we have been able to preserve the original 3 groupings of competencies, namely Workplace, Personal Effectiveness and Academic.

Both the Workplace and Academic competency categories have undergone a substantial change in terms of the reduced number of competencies (from 8 to 4 and from 6 to 3 respectively). Interestingly, the Personal effectiveness category is still made up of broadly the same competencies as previously, meaning that student perceptions of them are more distinct. Specifically, in the Personal effectiveness category only two of the competencies, 'drive, initiative and results focus' and 'adaptability and flexibility' have been consolidated to become 'flexibility and results focus'. The remaining four competencies have all been preserved. This leads us to the conclusion that Personal effectiveness competencies are all pervasive and contribute to the wellbeing of an individual in both academic and workplace environments. These competencies play a vital role in an individual's capacity to 'perform'.

We have achieved a tighter Workplace category centreing on business acumen and solution-driven characteristics, giving students an opportunity to sharpen their perception of the needs of the workplace.

We have also been able to condense the Academic category so that prominence is now given to study and IT skills. For the students in this sample, as they are on Computing-related degrees, the original 'fundamental IT skills' competency was seen to be closely related to 'working with tools and technology' and therefore no separation between them was made. However, if the competency 
framework was to be used generically to include all types of disciplines, then the 'fundamental' aspect may need to be reconsidered.

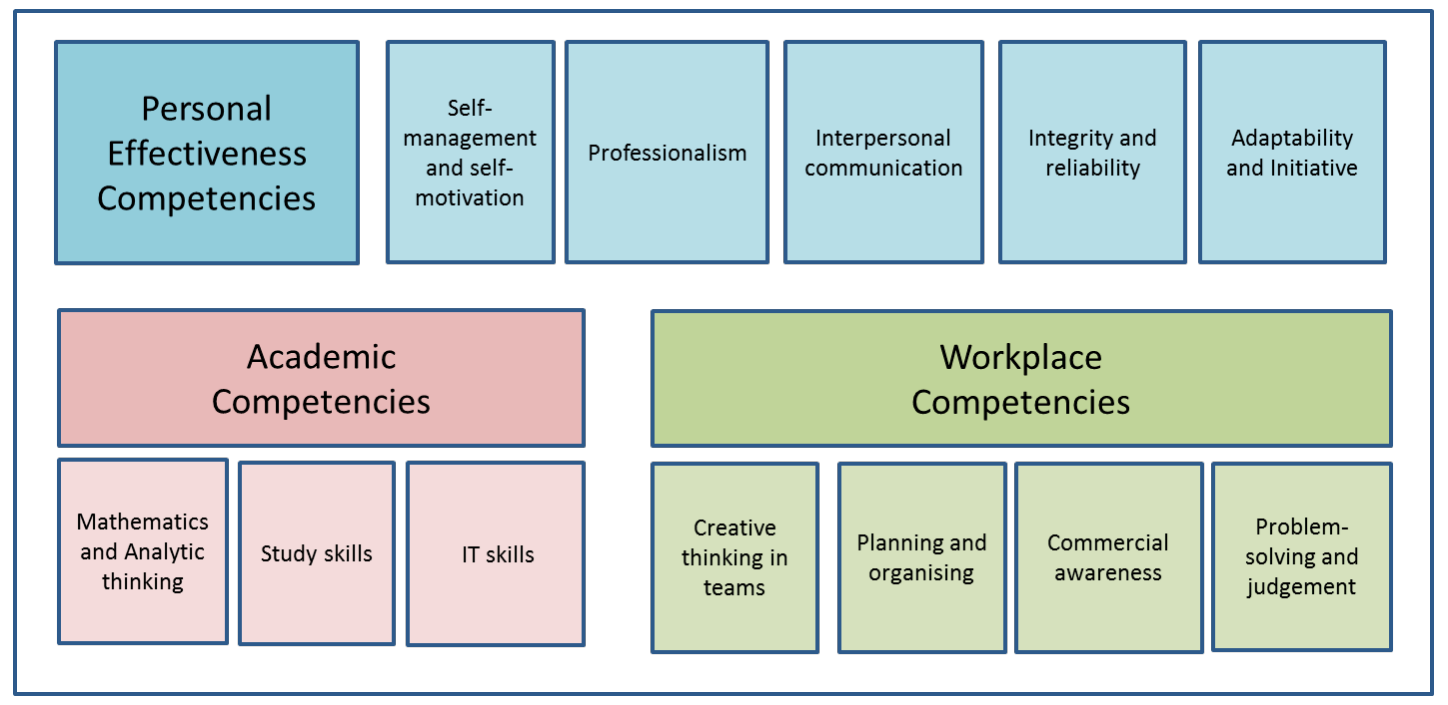

Figure 4 An Optimised Competency Framework for Work-Related Learning.

Cluster and correlation analysis have been useful in the investigation of competency scoring relationships. Some general points of interest include:

- The three original categories seem sensible and are useful to maintain; but we found much scope within each category to reconfigure and reduce.

- The reduction of correlated variables has allowed us to distil the 12 most important competencies. This is advantageous as students could now be exposed to a condensed version of the competency framework in the first place. In addition, assessments can be tailored to measure the improvement of these specific twelve skills.

- Within the optimised competency framework, competencies are now broadly orthogonal to encapsulate the importance of each one.

- Both types of analysis have shown that there are a handful of skills that stand apart from the 3 main categories and also from each other. These appear to be the competencies that many students would struggle to understand, practice and evidence. Developmental feedback in these areas could prove to be particularly beneficial, as it is during the course of the WRL experience that students may be able grapple with them in some grounded context.

\section{SUMMARY}

We have presented a competency framework intended for use by students on a degree programme which gives an opportunity for tutors to provide targeted developmental feedback and also an opportunity for students to self-evaluate themselves. We have been able to show, in the first instance, that students' scoring of their competency perceptions tends to be clustered around particular competencies. If the students are regarding and responding to competencies in a highly-clustered way, then there may be some redundancy and the cluster analysis shows several ways that the groups of competencies could potentially be viewed. Next, we were able to investigate the way in which competency scores were correlated, which led to a fruitful distillation of the original twenty competencies down to just twelve. The resulting optimised competency framework features personal effectiveness competencies prominently.

\section{REFERENCES}

[1] Bennani, S., Idrissi, M. K., Fadouli, N., Yassine, B. T. and Ouguengay. Y. A. "Online Project Based Learning Driven by Competencies." Proceedings of 2012 International Conference on Interactive Mobile and Computer Aided Learning (IMCL), November 6, 2012, 92-97. doi:10.1109/IMCL.2012.6396457. 
[2] Rivera-Ibarra, J.G., Rodriguez-Jacobo, J., Serrano-Vargas, M.A., 2010. Competency Framework for Software Engineers. Software Engineering Education and Training (CSEE\&T), 2010 23rd IEEE Conference on 33-40. doi:10.1109/CSEET.2010.21

[3] Ducrot, J., Shankararaman, V., 2014. Measuring student performance and providing feedback using Competency Framework. Engineering Education (ICEED), 2014 IEEE 6th Conference on 55-60. doi:10.1109/ICEED.2014.7194688

[4] Sedelmaier, Y., Landes, D., 2014. A multi-perspective framework for evaluating software engineering education by assessing students' competencies: SECAT - A software engineering competency assessment tool. Frontiers in Education Conference (FIE), 2014 IEEE 1-8. doi:10.1109/FIE.2014.7044331

[5] Hutchings, J., Corr, S., 2012. A Framework for Access to the Conservation-Restoration Profession via the Mapping of Its Specialist Competencies. Higher Education: The International Journal of Higher Education and Educational Planning 63, 439-454.

[6] Qing, B, Zhao, H., Xia, T., 2011. A Theoretical Framework for the Identifying, Assessment and Development of Competency of Border Officers. Management and Service Science (MASS), 2011 International Conference on 1-5. doi:10.1109/ICMSS.2011.5998103

[7] Jamaluddin, A., Ismail, A., Kamarudin, H.D., Idris, S.R.A., Othman, M.Z., 2014. Towards establishing medical records officer competency framework in healthcare providers. Information and Communication Technology (ICoICT), 2014 2nd International Conference on 193-198. doi:10.1109/ICoICT.2014.6914064

[8] Scholtz, B., Cilliers, C., Calitz, A., 2012. A Comprehensive, Competency-Based Education Framework Using Medium-Sized ERP Systems. Journal of Information Systems Education 23, 345-358.

[9] Krause, J., Dias, L.P., Schedler, C., 2015. Competency-Based Education: A Framework for Measuring Quality Courses. Online Journal of Distance Learning Administration 18.

[10] Johnson, B., Ulseth, R., 2014. Professional competency attainment in a project based learning curriculum: A comparison of project based learning to traditional engineering education. Frontiers in Education Conference (FIE), 2014 IEEE 1-4. doi:10.1109/FIE.2014.7044124

[11] Orsoni, A., Colaco, B., 2013. A Competency Framework for Software Development Organizations. Computer Modelling and Simulation (UKSim), 2013 UKSim 15th International Conference on 507-511. doi:10.1109/UKSim.2013.101 